\title{
Unusual Presentation of Pheochromocytoma with Polyphagia
}

\section{PRK Bhargav}

\section{ABSTRACT}

Pheochromocytoma is adrenal medullary tumor known to present in protean ways, especially in children. Here we describe a case of adrenal pheochromocytoma in young girl of 13 years presenting with polyphagia as a predominant symptom. She was successfully treated with laparoscopic adrenalectomy.

Keywords: Pheochromocytoma, Laparoscopic adrenalectomy, Polyphagia, Amaurosis fugax, Hypertension, Adrenal gland.

How to cite this article: Bhargav PRK. Unusual Presentation of Pheochromocytoma with Polyphagia. World J Endoc Surg 2014;6(3):113-114.

\section{Source of support: Nil}

Conflict of interest: None

\section{CASE REPORT}

A 13 years old girl presented with history of two self-limiting attacks of transient blackouts (amaurosis fugax) associated with palpitations since 1 month. During one of the episodes, the measured blood pressure was 210/120 mm $\mathrm{Hg}$. She was put on calcium channel blockers and fundus examination showed grade II hypertensive retinopathy. She was referred to us for further treatment as there was history of hypothyroidism too. Further history evoked the striking chief complaint of polyphagia with craving for bizarre foods, beverages and snacks, which were rarely savoured by her in the past. She was craving for non-vegetarian food, ice-creams, pizzas, chalk, raw rice. This craving was more marked at midnights and early mornings. Renal function tests were within normal limits. Computed tomography (CT) of brain and neurological examination was normal. Other causes of secondary hypertension, such as vasogenic and drug intake were excluded. On further evaluation, there were neither stigmata nor family history of MEN syndromes, paraganglioma, Carney's complex, neurofibromatosis or VHL syndrome. Twenty-four hour urinary metaneph-

\section{Consultant}

Department of Endocrine and Metabolic Surgery, Endocare Hospital, Vijayawada, Andhra Pradesh, India

Corresponding Author: PRK Bhargav, Consultant, Department of Endocrine and Metabolic Surgery, Endocare Hospital Vijayawada, Andhra Pradesh, India, Phone: 08742252010 e-mail: kingbhargav@gmail.com rines was diagnostic of adrenal pheochromocytoma with a level of $8.5 \mathrm{mg}$ (0.9-1.1). Computed tomography of abdomen revealed a $7.2 \times 6.5 \times 7.0 \mathrm{~cm}$ heterogeneously enhancing mass in right adrenal region (Fig. 1). She was preoperatively prepared with adequate hydration, escalating doses of prazosin from 1 to $8 \mathrm{mg}$ /day over 1 week period with her hemodynamic criteria meeting that of Roizen's criteria. Laparoscopic right adrenalectomy was done successfully with extirpation of a $8.0 \times 7.5 \times 7.4 \mathrm{~cm}$ encapsulated, highly vascular tumor (Fig. 2). Intraoperatively, there was usual blood pressure fluctuations with maximum of 190/110 mm $\mathrm{Hg}$ and minimum of 70/50 $\mathrm{mm} \mathrm{Hg}$, but it stabilized within 4 hours postoperatively. Postoperative period was uneventful and histopathology report was a benign pheochromocytoma. Final diagnosis was benign sporadic right pheochromocytoma.

\section{DISCUSSION}

Pheochromocytoma is known to be a great mimic due to its protean range of clinical presentations as it affects multiple organ systems. ${ }^{1,2}$ Though, the classical triad is severe headache, palpitations and sweating which is seen in $90 \%$ of cases, the clinical features could be atypical, mostly in extremes of age. ${ }^{3}$ As seen in the present case, this young girl had predominant symptoms of polyphagia and amaurosis fugax with absence of classical triad. The symptom of polyphagia is extremely rare, but not uncommonly seen in children and adolescents. ${ }^{3}$

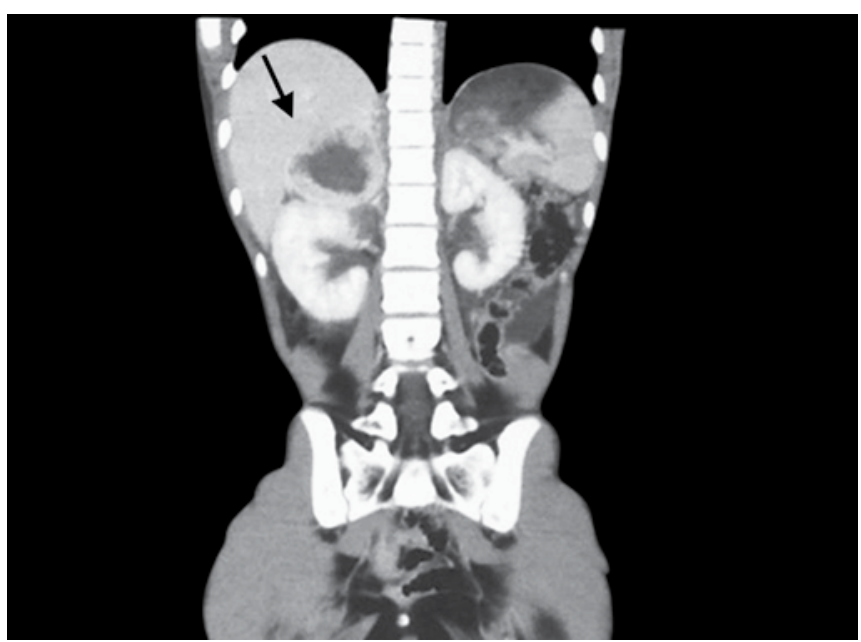

Fig. 1: Computerized tomogram of abdomen showing a heterodense mass lesion in right adrenal region (arrow) 


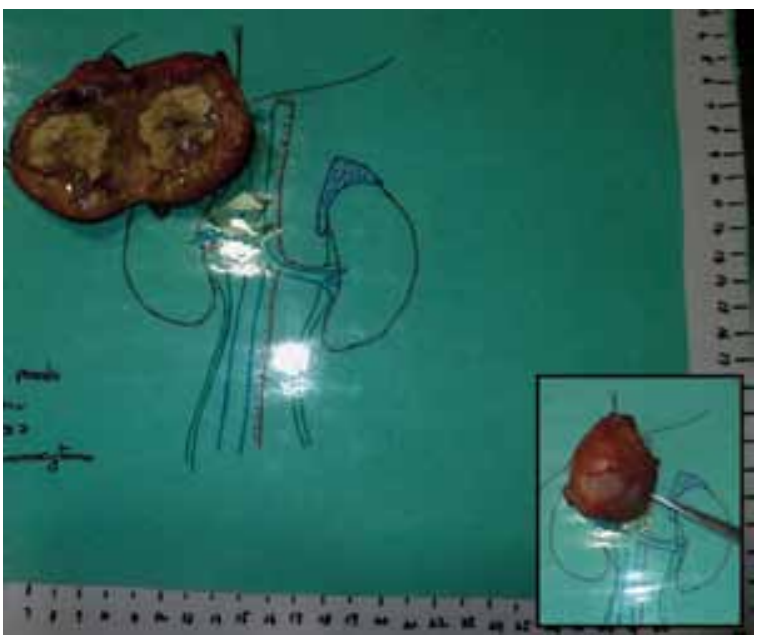

Fig. 2: Gross photograph of ex vivo right adrenalectomy specimen with tumor mass
The etiology of polyphagia is enigmatic, but its resolution after surgery suggests pheochromocytoma's causative role in this symptomatology.

Weconcludeby stating that, pheochromocytoma should be evaluated in any atypical clinical presentation with associated severehypertension in children and adolescents, especially in the absence of renal or neurological or vasogenic causes.

\section{REFERENCES}

1. DeCourcy JL, DeCourcy CB. Pheochromocytomas and the general practitioner. Cincinnati: Barclay Newman; 1952.p.163.

2. Bhargav PRK, Amar V. Pheochromocytoma is an eventful tumour: a case description. World J Endocr Surg 2010;2(3):139-141.

3. Hume DM. Pheochromocytoma in the adult and in the child. Am J Surg 1960;99:458-496. 